\title{
Laserowe wytwarzanie napoin twardych, trudnościeralnych i antykorozyjnych
}

\author{
Laser creation of padding welds \\ hard, abrasion- and corrosion resistant
}

\section{Streszczenie}

W pracy przedstawiono możliwość wytwarzania napoin laserowych na stali typu Hardox z zastosowaniem materiałów dodatkowych w postaci proszków o właściwościach antykorozyjnych, twardych i trudnościeralnych. Napoiny poddano testom mechanicznym i korozyjnym, na podstawie których wytypowano warstwy wierzchnie o najlepszych właściwościach w przewidywanych naturalnych warunkach eksploatacyjnych. W czasie testów wzięto pod uwagę morfologię i skład chemiczny proszków, zastosowane parametry procesowe, geometrię napoin, mikrostrukturę napoin, środowisko pracy, skład fazowy napoin, rozkład pierwiastków w napoinie i SWC, mikrotwardość napoin, odporność na ścieranie, erozję oraz odporność na korozję.

Słowa kluczowe: laser; napawanie; dodatkowe materiały proszkowe
Abstract

The work shows the ability to create laser padding welds of steel as Hardox type with the use of additional materials in the form of powders on the properties of hard, abrasion- and corrosion resistant. The padding welds were subjected to mechanical and corrosion tests, based on which the top layers with the best properties in the predicted natural operating conditions were selected. At the time of testing have been taken into account the morphology and chemical composition of powders, applied process parameters, geometry of padding welds, the microstructure, operating environment, the phase composition of padding welds, the distribution of elements in the padding weld and the HAZ, microhardness, resistance to erosion and corrosion resistance.

Keywords: laser; pad welding; filler powders

\section{Przebieg eksperymentu i wyniki badań}

Zapewnienie dobrej jakości napoin poprzedzono próbami doboru parametrów procesowych zapewniających oczekiwany rezultat w postaci napoin o relatywnie znacznej wysokości nadlewu i małej głębokości wtopienia i przez to małej zawartości składników podłoża w napoinach (rys. 2, 3 i 10, tabl. V, VI i XIII). Podobne pomiary przeprowadzono $\mathrm{w}$ pracach $[2 \div 4]$. Właściwości napoin określono w teście przeprowadzonym w rzeczywistych warunkach eksploatacyjnych (rys. 4, tabl. VII), gdzie podobne pomiary jakości gleby wykonali autorzy prac $[5,6]$. We wszystkich wariantach parametrów procesowych oczekiwano powstałej SWC o małym zasięgu, która nie stanowi zagrożenia w warunkach obciążenia eksploatacyjnego napoin.

Tablica I. Skład chemiczny stali Hardox 500 [1]

Table I. Chemical composition of the Hardox 500 steel [1]

\begin{tabular}{|c|c|c|c|c|c|c|c|c|c|c|}
\hline \multirow{2}{*}{ stal } & \multicolumn{9}{|c|}{ pierwiastek, \% wag. } & \multirow{2}{*}{$\mathrm{C}_{\mathrm{EV}}$} \\
\hline & C & $\mathrm{Si}$ & Mn & $\mathbf{P}$ & s & $\mathrm{Cr}$ & $\mathrm{Ni}$ & Mo & B & \\
\hline Hardox 500 & 0,290 & 0,700 & 1,600 & 0,025 & 0,010 & 1,000 & 0,500 & 0,0300 & 0,004 & 0,62 \\
\hline
\end{tabular}

Dr inż. Artur Wypych - Politechnika Poznańska.

Autor korespondencyjny/Corresponding author: artur.wypych@put.poznan.pl 
Tablica II. Wybrane właściwości stali Hardox 500 [1]

Table II. Selected properties of the Hardox 500 steel [1]

\begin{tabular}{|c|c|c|c|c|c|}
\hline \multirow{2}{*}{ stal } & \multicolumn{5}{|c|}{ parametr } \\
\hline & $\mathrm{HB}$ & $\begin{array}{c}\mathbf{R}_{\mathrm{p} 0,2}, \\
\mathrm{MPa}\end{array}$ & $\mathbf{R}_{\mathrm{m}}, \mathrm{Mpa}$ & $\mathbf{A}_{5,} \%$ & $\mathrm{KV}_{-40,} \mathbf{J}$ \\
$\begin{array}{c}\text { Hardox } \\
500\end{array}$ & 505 & 1300 & 1550 & 8 & 30 \\
\cline { 2 - 6 } & & & & & \\
\hline
\end{tabular}

Tablica IV. Zakres wielkości większościowej ilości drobin proszków Table IV. Size range of majority amount of powder particles

\begin{tabular}{|c|c|}
\hline nr proszku & zakres wielkości drobin, $\boldsymbol{\mu m}$ \\
\hline 1 & $70 \div 130$ \\
\hline 2 & $50 \div 100$ \\
\hline 3 & $60 \div 90$ \\
\hline 4 & $50 \div 100$ \\
\hline
\end{tabular}
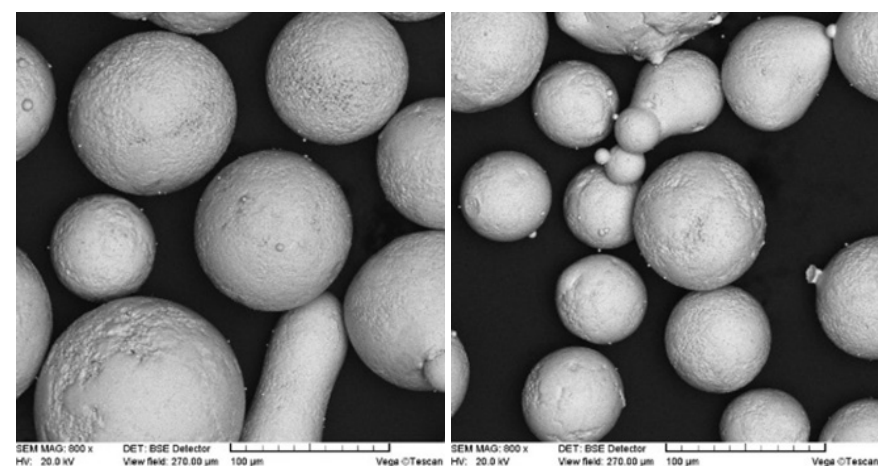

Rys. 1. Widok drobin proszku; topografia drobin (SE) i niejednorodność składu chemicznego w obrębie pojedynczych drobin (BSE), kolejność próbek od lewej 1,2,3,4

Fig. 1. View the powder particles; the topography of particles (SE) and heterogeneity of the chemical composition within individual particles (BSE), the order of samples from left 1,2,3,4

Tablica III. Wynik mikroanalizy chemicznej materiałów powłokowych w postaci proszków Table III. Result of chemical microanalysis of coating materials in the form of powders

\begin{tabular}{|c|c|c|c|c|c|c|c|c|}
\hline \multirow{2}{*}{ pierwiastek } & \multicolumn{2}{|c|}{1} & \multicolumn{2}{|c|}{2} & \multicolumn{2}{|c|}{3} & \multicolumn{2}{|c|}{4} \\
\hline & \%wag. & atest & \%wag. & atest & \%wag. & atest & \%wag. & atest \\
\hline $\mathrm{Ni}$ & 70,53 & reszta & 72,63 & reszta & - & - & - & - \\
\hline Mo & - & - & - & - & 13,68 & 9,1 & 13,39 & 9,00 \\
\hline Mn & - & - & - & - & 0,91 & 0,38 & 0,90 & 0,36 \\
\hline $\mathrm{Cr}$ & 19,41 & 17,00 & 17,84 & 17,00 & 20,65 & 21,80 & 20,53 & 21,50 \\
\hline $\mathrm{Fe}$ & 4,02 & 4,00 & 3,84 & 4,00 & - & - & - & - \\
\hline Si & 6,04 & 4,00 & 5,69 & 4,00 & 0,51 & 0,39 & 0,44 & 0,40 \\
\hline 0 & - & - & - & - & 3,88 & 0,07 & - & - \\
\hline W & 17,89 & - & 21,32 & - & 16,23 & - & 23,12 & - \\
\hline B & 1,19 & 3,00 & 1,52 & 1,60 & 1,65 & 1,5 & 1,45 & 2 \\
\hline $\mathrm{Nb}$ & - & - & - & - & 5,53 & 3,52 & 5,87 & 3,62 \\
\hline
\end{tabular}

Tablica V. Podstawowe parametry procesowe zastosowane w eksperymencie Table V. The basic process variations used in the experiment

\begin{tabular}{|c|c|c|c|c|c|c|c|c|c|}
\hline \multirow{2}{*}{ nr próbki } & \multirow{2}{*}{ materiał rodzimy } & \multicolumn{2}{|c|}{ palmka } & \multirow{2}{*}{$\mathrm{V}, \mathrm{mm} / \mathrm{s}$} & \multirow{2}{*}{$\mathrm{P}, \mathrm{kW}$} & \multirow{2}{*}{$\begin{array}{c}\mathrm{Q}, \\
\mathrm{J} / \mathrm{mm}^{2} / \\
\mathrm{mm}\end{array}$} & \multicolumn{2}{|c|}{ gaz, Ar $99,99 \%, 1 / \min$} & \multirow{2}{*}{$\begin{array}{r}\begin{array}{r}\text { mat. } \\
\text { dodat }\end{array} \\
\mathrm{g} / \mathrm{min}\end{array}$} \\
\hline & & bok a & bok b & & & & transp. & ost. & \\
\hline 1 & S235JR/ Hardox 500 & 24 & 3 & 8 & 10 & 17,36 & 10 & 22 & 156 \\
\hline 2 & S235JR/ Hardox 500 & 24 & 6 & 5 & 10 & 13,89 & 10 & 22 & 156 \\
\hline 3 & S235JR/ Hardox 500 & 24 & 6 & 5 & 8 & 11,11 & 10 & 22 & 156 \\
\hline 4 & S235JR/ Hardox 500 & 24 & 3 & 6 & 10 & 23,15 & 10 & 22 & 156 \\
\hline
\end{tabular}




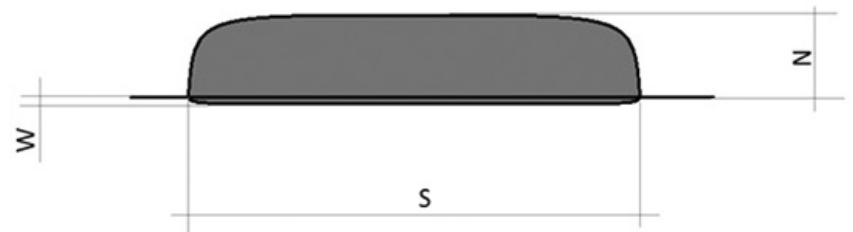

Rys. 2. Schemat opisujący geometrię napoin

Fig. 2. Diagram describing the geometry of padding welds

Tablica VI. Wartość parametrów opisujących geometrię napoin Table VI. Parameters value that describe the geometry of padding welds

\begin{tabular}{|c|c|c|c|}
\hline parametr & $\begin{array}{c}\text { wysokość } \\
\text { nadlewu N, } \\
\mathbf{m m}\end{array}$ & $\begin{array}{c}\text { szerokość lica } \\
\text { S, mm }\end{array}$ & $\begin{array}{c}\text { głębokość } \\
\text { wtopienia W, } \\
\mathbf{m m}\end{array}$ \\
\hline wartość & $0,5 \div 8$ & 22 & $0,1 \div 1$ \\
\hline
\end{tabular}

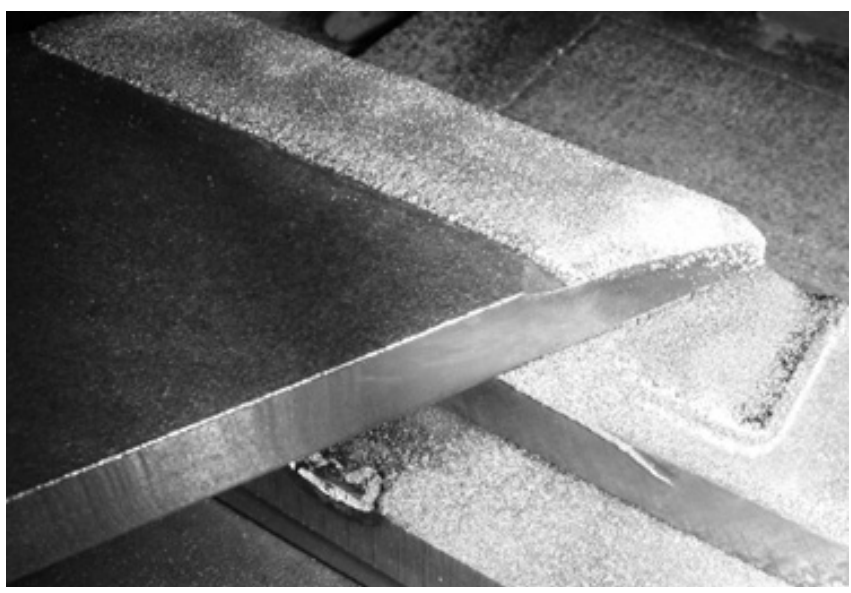

Rys. 3. Widok próbnych detali z wytworzoną napoiną laserową na stanowisku spawalniczym

Fig. 3. On welding stand specimen view with created laser padding weld
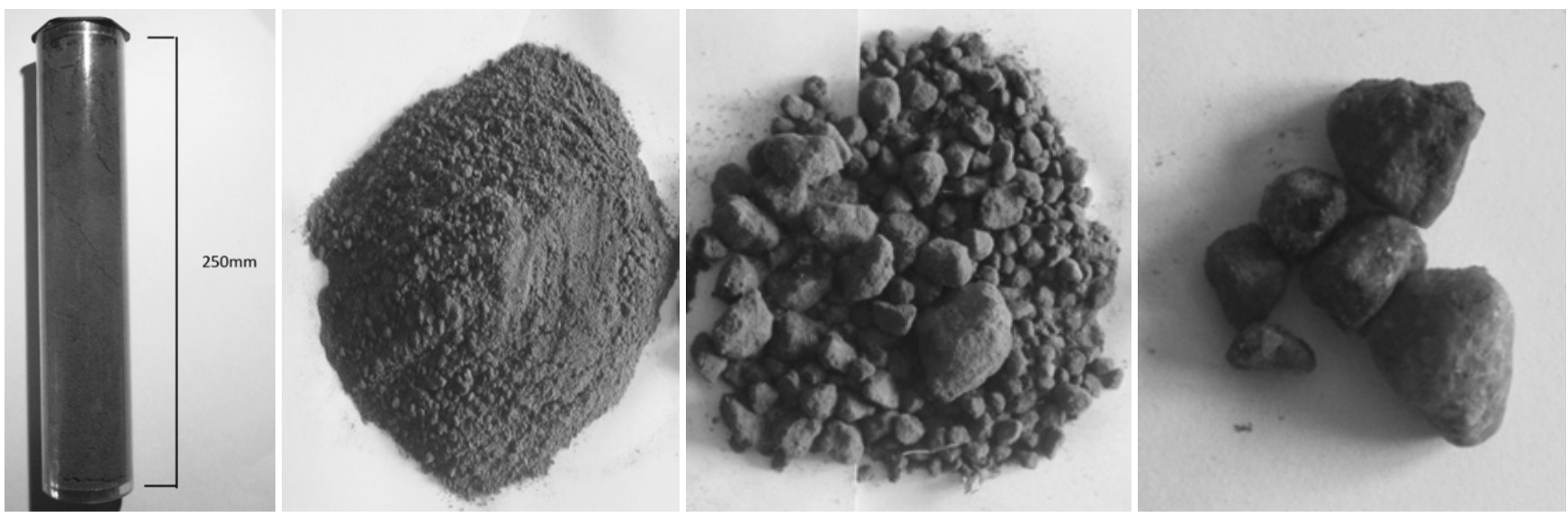

Rys. 4. Widok składników złoża zawierającej część sypką w 77\% wag., drobne kruszywo 15\% wag., grube kruszywo w $8 \%$ wag Fig. 4. View of the components of the deposits containing part of the loose in $77 \%$, fine aggregate in $15 \%$, coarse aggregate in $8 \%$

Tablica VII. Wynik wielkości zużycia detali poprzez określenie ich długości po teście w jednakowych warunkach obciążenia Table VII. The result of the consumption of parts by specifying their length after the test in the same load conditions

\begin{tabular}{|c|c|}
\hline stan detali & długość, mm \\
\hline w stanie dostawy & 330 \\
\hline po teście z napoiną laserową z wykorzystaniem materiału 1 & 297 \\
\hline dłuta po teście zabezpieczonego napoiną laserową z wykorzystaniem materiału 2 & 278 \\
\hline dłuta po teście bez napoiny zabezpieczającej & 225 \\
\hline
\end{tabular}

Tablica VIII. Wyniki pomiaru porowatości powłok i napoin Table VIII. The results of porosity measurement of coatings and padding welds

\begin{tabular}{|c|c|}
\hline nr próbki & porowatość, \% \\
\hline 1 & pojedyncze pory, brak mikroporowatości \\
\hline 2 & pojedyncze pory, brak mikroporowatości \\
\hline 3 & pojedyncze pory, brak mikroporowatości \\
\hline 4 & pojedyncze pory, brak mikroporowatości \\
\hline
\end{tabular}

Tablica IX. Wyniki pomiaru grubości napoin i zasięgu SWC

Table IX. The results of thickness measurement of padding welds and $\mathrm{HAZ}$ range

\begin{tabular}{|c|c|c|}
\hline nr próbki & grubość, $\boldsymbol{\mu m}$ & zasięg SWC, $\boldsymbol{\mu m}$ \\
\hline 1 & 1200 & 1300 \\
\hline 2 & 1500 & 1300 \\
\hline 3 & 800 & 900 \\
\hline 4 & 650 & 1250 \\
\hline
\end{tabular}



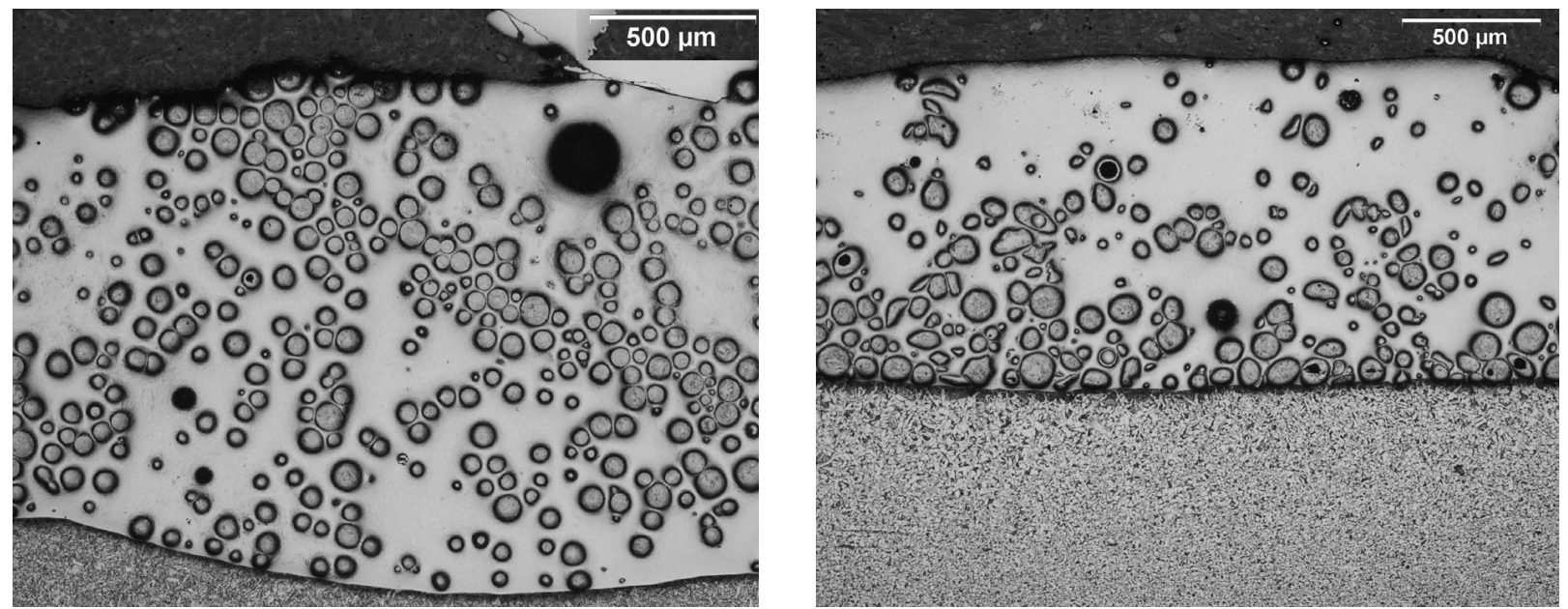

Rys. 5. Widok mikrostruktury wytworzonej warstwy i materiału rodzimego na powierzchni przekroju poprzecznego, głębokość największych porów wynosi $125 \mu \mathrm{m}$ - od lewej próbka 2 i 3

Fig. 5. View of the microstructure produced layer and base material on the surface of the cross section, the depth of the largest pore is $125 \mu \mathrm{m}$ - from the left sample 2 and 3
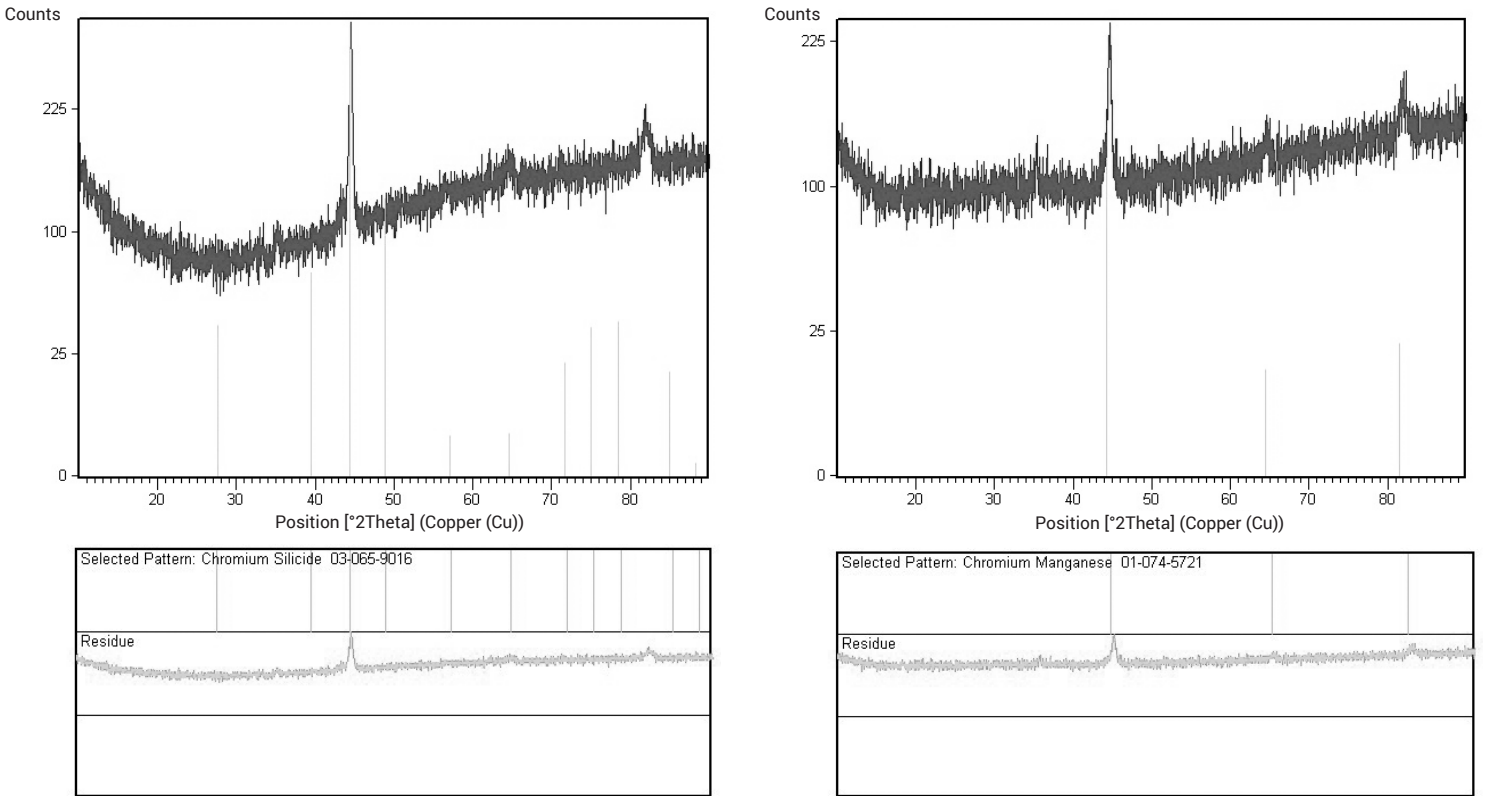

Rys. 6. Dyfrakcyjne widmo rentgenowskie pochodzące od $\mathrm{Cr}_{3} \mathrm{Si}$ oraz $\mathrm{CrMn}$

Fig. 6. Diffractive x-ray spectrum from $\mathrm{Cr}_{3} \mathrm{Si}$ and the $\mathrm{CrMn}$
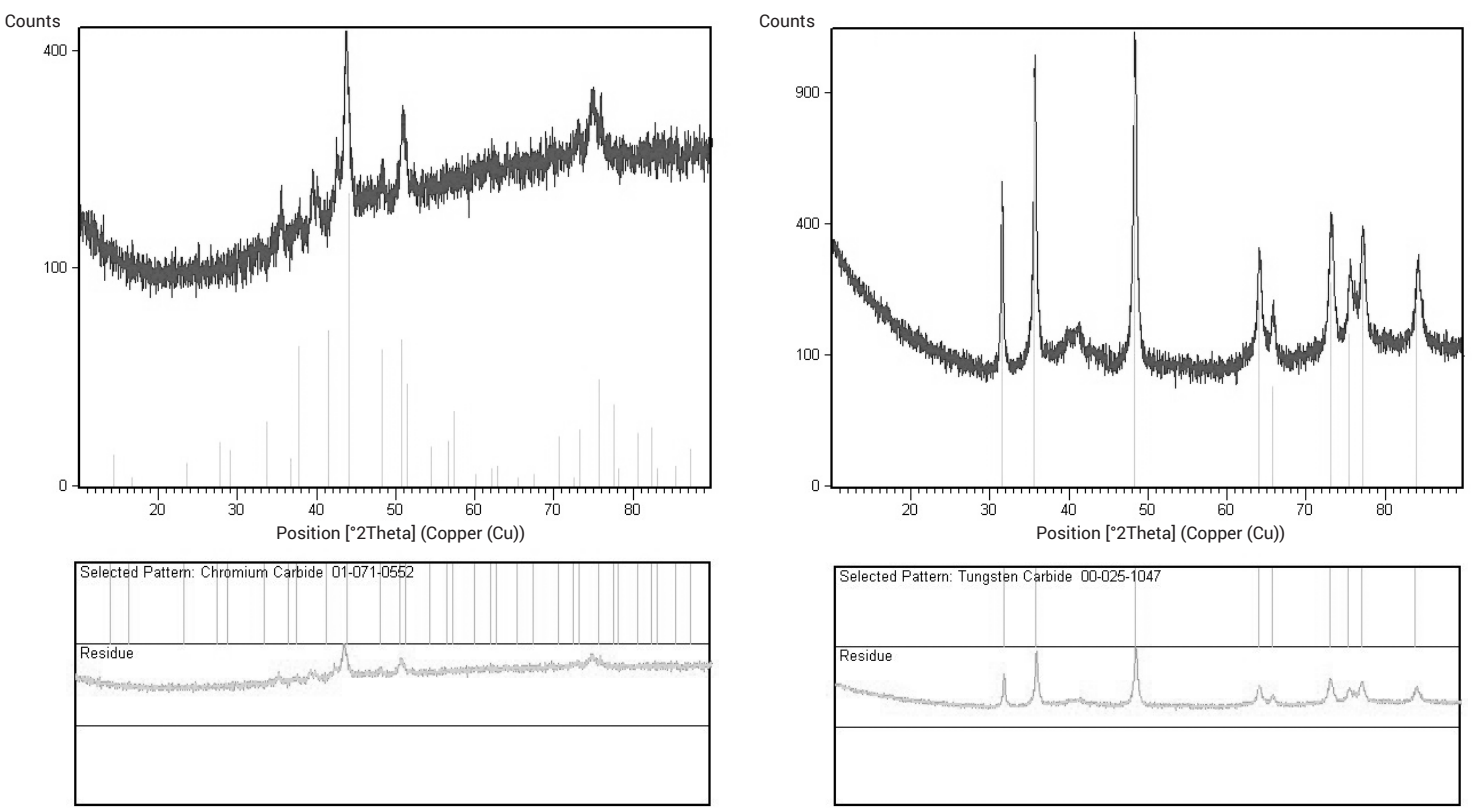

Rys. 7. Dyfrakcyjne widmo rentgenowskie pochodzące od $\mathrm{Cr}_{23} \mathrm{C}_{6}$ oraz WC

Fig. 7. Diffractive x-ray spectrum from $\mathrm{Cr}_{23} \mathrm{C}_{6}$ and the WC 

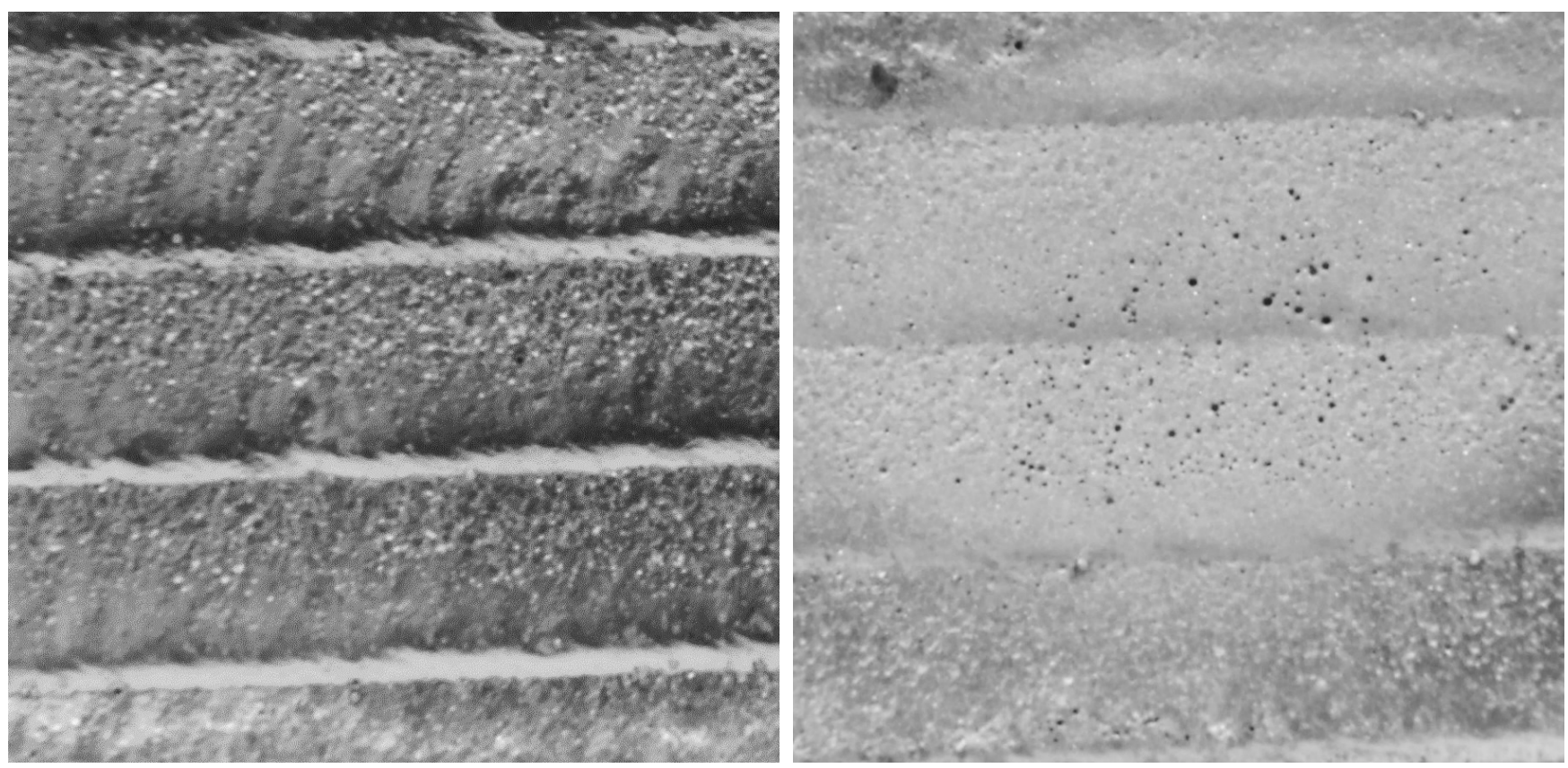

Rys. 8. Widok powierzchni przed testem erozyjnym - z lewej i poddanej testowi - z prawej, próbka 3

Fig. 8. View of the surface before the erosion test - left and put to the test - right, sample 3

Tablica X. Wyniki pomiaru twardości w wytworzonych warstwach wierzchnich

Table $\mathbf{X}$. The results of hardness measurement in the manufactured surface layers

\begin{tabular}{|c|c|}
\hline \multirow{2}{*}{$\begin{array}{c}\text { nr } \\
\text { próbki }\end{array}$} & warstwa wierzchnia \\
\hline & twardość HV0,3 \\
\hline 1 & $\begin{array}{c}\text { lico-osnowa: 558, min: 518, max: 593; } \\
\text { lico-węglik owalny: 2596, min: 2494, max: 2698; } \\
\text { lico-węglik sferoidalny: 2797, min: 2682, max: } 2864\end{array}$ \\
\hline 2 & $\begin{array}{l}\text { lico-osnowa: } 651, \min : 621, \max : 683 ; \\
\text { lico-węglik sferoidalny: 3191, min: } 3169, \max : 3222 ; \\
\text { połowa-osnowa: } 798, \min : 789, \max : 821 ; \\
\text { grań-osnowa: } 743, \min : 711, \max : 767 ; \\
\text { grań-węglik sferoidalny: } 3071, \min : 3012, \max : 3129\end{array}$ \\
\hline 3 & $\begin{array}{l}\text { lico-osnowa: 456, min: 415, max: 486; } \\
\text { lico-węglik: } 3165, \min : 3099, \max : 3222\end{array}$ \\
\hline 4 & $\begin{array}{l}\text { lico-osnowa: 651, min: 533, max: 899; } \\
\text { lico-węglik: } 3075 \text {, min: } 2797, \max : 3253\end{array}$ \\
\hline
\end{tabular}

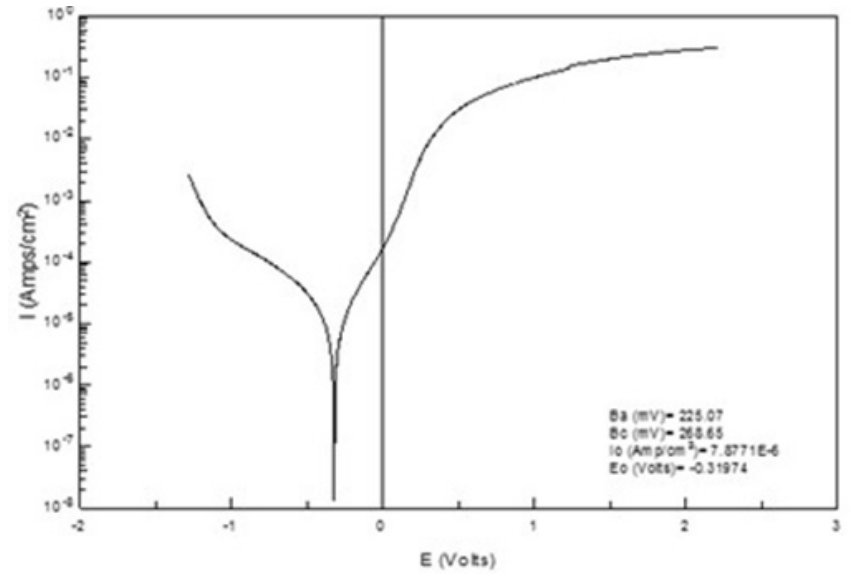

Rys. 9. Wynik badania potencjostatycznego napoin - napoina 4 Fig. 9. The result of the padding welds potentiostatic test - padding weld 4
Tablica XI. Wyniki pomiaru odporności warstw na zużycie ścierne Table XI. The results of resistance measurement on abrasive wear of the layers

\begin{tabular}{|c|c|c|c|c|}
\hline $\begin{array}{c}\text { oznaczenie } \\
\text { próbki }\end{array}$ & $\begin{array}{c}\mathbf{m}_{\mathbf{0}}, \\
\mathbf{g}\end{array}$ & $\begin{array}{c}\mathbf{m}_{\mathbf{k}}, \\
\mathbf{g}\end{array}$ & $\begin{array}{c}\mathbf{\Delta} \mathbf{m}, \\
\mathbf{g}\end{array}$ & $\begin{array}{c}\mathbf{\Delta V}, \\
\mathbf{m m}^{3}\end{array}$ \\
\hline 1 & 805,33 & 805,26 & 0,07 & 8,29 \\
\hline 2 & 768,96 & 768,92 & 0,04 & 4,74 \\
\hline 3 & 771,52 & 771,37 & 0,15 & 17,80 \\
\hline 4 & 846,36 & 846,14 & 0,22 & 26,01 \\
\hline stal & 1032,87 & 1031,39 & 1,48 & 173,98 \\
\hline
\end{tabular}

Tablica XII. Różnica grubości warstw w wyniku próby odporności erozyjnej, $\mathrm{t}=60 \mathrm{~s}$, kąt strumienia $45^{\circ}$ i $90^{\circ}$

Table XII. Difference in layer thickness due to erosion resistance test, $\mathrm{t}=60 \mathrm{~s}$, stream angle $45^{\circ}$ and $90^{\circ}$

\begin{tabular}{|c|c|c|c|c|c|}
\hline nr próbki & 1 & 2 & 3 & 4 & stal \\
\hline kąt strumienia ścierniwa, $^{\circ}$ & \multicolumn{5}{|c|}{45} \\
\hline różnica grubości warstwy, $\mu \mathrm{m}$ & 70 & 60 & 100 & 80 & 370 \\
\hline kąt strumienia ścierniwa, ${ }^{\circ}$ & \multicolumn{5}{|c|}{90} \\
\hline różnica grubości warstwy, $\mu \mathrm{m}$ & 60 & 100 & 110 & 90 & 340 \\
\hline
\end{tabular}

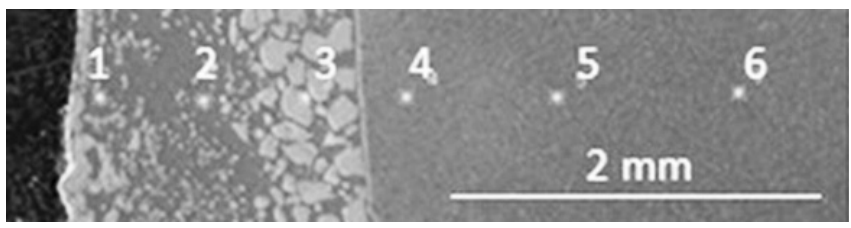

Rys. 10. Widok przekroju poprzecznego przykładowej napoiny z zaznaczonymi punktami pomiaru zawartości pierwiastków w napoinie i materiale rodzimym

Fig. 10. Cross section view of padding welds with the selected measurement points of the elements content in padding welds and base material 
Tablica XIII. Wynik mikroanalizy chemicznej napoiny i materiału rodzimego

Table XIII. The result of the chemical microanalysis of padding weld and base material

\begin{tabular}{|c|c|c|c|c|c|c|}
\hline $\begin{array}{c}\text { pier- } \\
\text { wia- } \\
\text { stek }\end{array}$ & $\begin{array}{c}\text { punkt } \\
\mathbf{1}\end{array}$ & $\begin{array}{c}\text { punkt } \\
\mathbf{2}\end{array}$ & $\begin{array}{c}\text { punkt } \\
\mathbf{3}\end{array}$ & $\begin{array}{c}\text { punkt } \\
\mathbf{4}\end{array}$ & $\begin{array}{c}\text { punkt } \\
\mathbf{5}\end{array}$ & $\begin{array}{c}\text { punkt } \\
\mathbf{6}\end{array}$ \\
\hline & \multicolumn{7}{|c|}{ zawartość \%wag. } \\
\hline $\mathrm{Ni}$ & 66,08 & 76,33 & 33,13 & 0,00 & 0,00 & 0,00 \\
\hline $\mathrm{Si}$ & 0,10 & 0,69 & 0,00 & 0,13 & 0,17 & 0,14 \\
\hline $\mathrm{W}$ & 25,57 & 15,11 & 61,21 & 0,00 & 0,00 & 0,00 \\
\hline $\mathrm{Fe}$ & 7,05 & 6,20 & 5,12 & 95,69 & 99,83 & 99,86 \\
\hline $\mathrm{B}$ & 1,19 & 1,68 & 0,55 & 4,18 & 0,00 & 0,00 \\
\hline
\end{tabular}
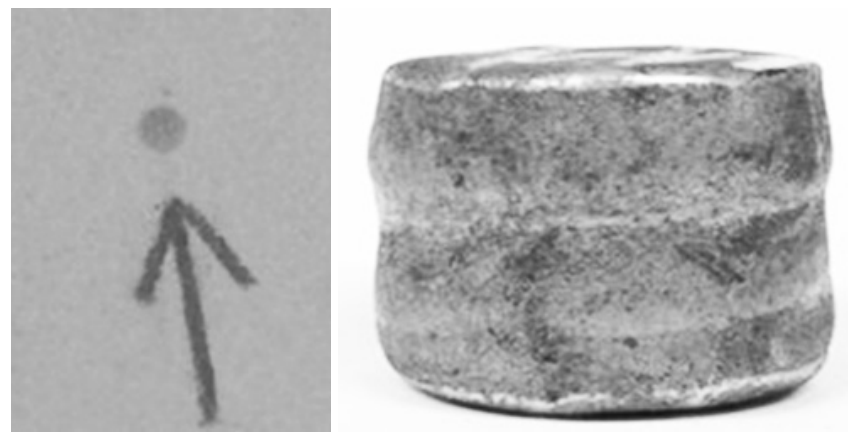

Rys. 11. Widok powierzchni napoiny po obciążeniu testowym zgodnie z VDI 3198 oraz teście korozyjnym - napoina 2

Fig. 11. View of the surface after loading test in accordance with VDI 3198 and corrosive test -padding weld 2

\section{Podsumowanie i wnioski}

W napoinach stwierdzono występowanie porów niezagrażających właściwościom ochronnym warstwy w obecności naprężeń mechanicznych i łagodnego obciążenia korozyjnego. Możliwe jest wyeliminowanie porowatości poprzez zapewnienie większej czystości w zakresie doboru i przygotowania podłoża lub doboru i przygotowania proszku przed napawaniem poprzez jego dokładne wymieszanie i osuszenie (rys. 1 i 5, tabl. I - IV i VIII). Napoiny nr 1, 3, 4 charakteryzują się segregacją węglików w objętości warstwy, gdzie znacznie większa koncentracja węglików przy linii wtopienia wpłynie na przyspieszone zużycie warstwy ochronnej w pierwszym etapie eksploatacji, a dopiero w późniejszym etapie uzyskana zostanie właściwa zdolność ochronna warstwy (rys. 5). W przypadku napoiny 4 powstała SWC ma zasięg dwukrotnie większy niż grubość napoin. Podobna sytuacja, lecz o mniejszych wzajemnych proporcjach występuje w przypadku napoin 1, 3 (tabl. IX). Skład fazowy napoin wynika bezpośrednio z rodzaju i zawartości poszczególnych pierwiastków, gdzie powstałe fazy są adekwatne do zastosowanych stopów. Jednocześnie nie stwierdzono pików dyfrakcyjnych, które wskazywałyby na tworzenie się niekorzystnych faz czy związków (rys. 6 i 7). Twardość w skali Vickers'a wykazuje znaczne zróżnicowanie w warstwach w osnowie i w obszarze występowania węglików (tabl. X). Największą odporność na obciążenia pod kątem $45^{\circ}$ wykazuje próbka $1 \mathrm{~b}$ oraz pod kątem $90^{\circ}$ - próbka 1 (rys. 8, tabl. XII). W teście erozyjnym w żadnym przypadku nie stwierdzono degradacji napoin w postaci ich odpadania od podłoża na skutek niewystarczającej przyczepności, zwłaszcza w agresywnej konfiguracji pod kątem $45^{\circ}$ do podłoża. Podobne badania jakości warstw wierzchnich opisano w pracach 7 i 8 . Wszystkie warstwy wykazują dobrą jakość zgodnie z testem wg normy VDI (rys. 11). W próbie korozyjnej we mgle solnej wystąpiły ślady korozji w przypadkowych miejscach poza liniami wtopienia wzdłuż pokrywania się napoin układanych obok siebie (rys. 11). Wyniki podobnych badań korozyjnych zamieszczono w pracy [10]. Stopień pokrywania napoin w proc. szerokości ściegu może być niewielki z jednoczesnym zapewnieniem skutecznej ochrony rdzenia przed obciążeniem ściernym i korozyjnym (tabl. XI). Wszystkie napoiny wykazały dobrą odporność na warunki eksploatacyjne. Napoiny wykazują dobrą odporność na środowisko korozyjne w warunkach mgły solnej zarówno na powierzchniach, jak i strefie łączenia napoin wielościegowych - wzdłuż linii wtopienia. Wytworzone wierzchnie warstwy ochronne charakteryzują się dobrą odpornością korozyjną określoną w teście potencjostatycznym (rys. 9), gdzie badania o podobnym profilu opisano w pracy [9]. Najlepsze właściwości ochronne zapewnia napawanie zgodnie z parametrami dla napoiny 2 z zastosowaniem materiału proszkowego o zawartości $60 \%$ sferoidalnych węglików wolframu (WSC) i 40\% osnowy zawierającej nikiel i związki niklu z borem.

\section{Literatura}

[1] SSAB-Oxelösund

[2] Materiały konferencyjne: High-Power Diode Laser Technology and Applications XII, Proceedings of SPIE - The International Society for Optical Engineering, Vol. 8965, 2014.

[3] H. Zhu, M. Hao, J. Zhang, W. Ji, X. lin, J. Zhang, Y. Ning: Development and thermal management of $10 \mathrm{~kW}$, direct diode laser source, Optics and Laser Technology, Vol. 76, pp. 101-105, 2016.

[4] S. Brookshier, J. Washko, K. Parker, F. Gaebler, W Juchmann: The use of novel, direct diode lasers for large area hard-facing and high deposition rate cladding to enhance surface wear and corrosion resistance, Proceedings of SPIE - The International Society for Optical Engineering, Vol. 8239, article number $82390 \mathrm{H}, 2012$.

[5] A. Zhao, S. Xu, W. Zeng, F. Qu, X. Ma: Analysis of unstable farmland in arid and semi-arid regions and feasibility evaluation of its conversion, Nongye Gongcheng Xuebao/Transactions of the Chinese Society of Agricultural Engineering, Vol. 32, Issue 17, pp. 215-225, 2016.

[6] V. Cherlinka: Models of soil fertility as means of estimating soil quality, Geographia Cassoviensis, Vol. 10, Issue 2, pp. 131-147, 2016.
[7] D. Janicki, J. Górka, A. Czupryński, W. Kwaśny, M. Zuk: Diode laser cladding of Co-based composite coatings reinforced by spherical WC particles, Proceedings of SPIE - The International Society for Optical Engineering, Vol. 10159, Article number 101590N, 2016.

[8] P. Farahmand, R. Kovacevic: Corrosion and wear behavior of laser cladded Ni-WC coatings, Surface and Coatings Technology, Vol. 276, pp. 121-135, 2015.

[9] R. Awasthi, G. Abraham, S. Kumar, (...), D. Srivastava, G.K. Dey: Corrosion Characteristics of Ni-Based Hardfacing Alloy Deposited on Stainless Steel Substrate by Laser Cladding, Metallurgical and Materials Transactions A: Physical Metallurgy and Materials Science, Vol. 48, Issue 6, pp. 2915-2926, 2017.

[10] T.S. Mintz, D.S. Dunn: Atmospheric chamber testing to evaluate chloride induced stress corrosion cracking of type $304,304 \mathrm{~L}$, and $316 \mathrm{~L}$ stainless steel, NACE - International Corrosion Conference Series 2009, 20 p, Code 7705, Corrosion 2009. 